\title{
COESÃO TEXTUAL NA ESCRITA DE UM GRUPO DE ADULTOS SURDOS USUÁRIOS DA LÍNGUA DE SINAIS BRASILEIRA
}

\author{
Text cohesion in writing of a group of deaf adults users \\ of Brazilian sign language
}

\author{
Elizabeth Oliveira Crepaldi de Almeida ${ }^{(1)}$, Carolina Ronqui Filasi ${ }^{(2)}$, Luiza Crepaldi de Almeida ${ }^{(3)}$
}

\begin{abstract}
RESUMO
Objetivos: investigar a coesão textual em produções escritas por quatro adultos surdos usuários da Língua de Sinais Brasileira alfabetizados, integrantes de um grupo de discussão nessa língua, sobre o tema violência, coordenado por uma intérprete fluente. Verificar a possível interferência da Libras na escrita em português. Métodos: após terem participado de sessões de discussão sobre o tema violência, cada participante produziu um texto relacionado a algum tipo de violência. Seus textos foram analisados qualitativamente em termos de sua coesão. Resultados: os textos produzidos faziam referência a situações de violência simbólica. O estudo dos textos evidenciou presença de coesão textual sequencial e referencial em todos os textos, embora comprometida. Houve interferência da Libras nas redações. Observou-se que os textos, por si sós, são difíceis de serem compreendidos sem a interação direta com o participante. Apesar da dificuldade na compreensão da língua escrita, que é diferente da estrutura da língua de sinais, o estudo evidenciou que esses surdos podem construir textos com sentido e coesão. Conclusão: a produção escrita dos surdos pesquisados apresenta coesão, porém com interferência da Libras, o que prejudica, em alguns casos, a compreensão por parte do leitor. Quanto menor a coesão textual, maior a necessidade de explicações do autor sobre o que quis dizer com seu texto.
\end{abstract}

DESCRITORES: Surdez; Linguagem; Redação; Educação

\section{INTRODUÇÃO}

Estudos apontam que surdos não conseguem usar a escrita como alternativa para a comunicação com ouvintes ou para obtenção de informações ${ }^{1-3}$. Também há evidências de que, apesar de frequentarem a escola por longo tempo, apresentam baixo rendimento escolar ${ }^{3-5}$. Essas dificuldades, sobretudo no Brasil, podem ser atribuídas, pelo menos

(1) Fonoaudióloga; Professora titular do Curso de Fonoaudiologia da Pontifícia Universidade Católica de Campinas, PUCCAMP, Campinas, SP; Doutora em Educação pela Universidade Estadual de Campinas.

(2) Aluna do Curso de Graduação em Fonoaudiologia da Pontifícia Universidade Católica de Campinas, PUCCAMP, Campinas, SP; Bolsista de Iniciação Científica da Fundação de Amparo à Pesquisa do Estado de São Paulo, FAPESP

(3) Aluna do Curso de Medicina da Pontifícia Universidade Católica de Campinas, PUCCAMP, Campinas, SP.

Conflito de interesses: inexistente em parte, ao processo educativo escolar, em que mesmo alunos ouvintes sem qualquer comprometimento real apresentam dificuldades na aprendizagem da língua escrita.

Em um estudo com dois adultos surdos sobre a compreensão do conceito de violência ${ }^{2}$, por meio de análise semiótica, verificou-se que na escrita havia uma mescla das regras da Libras e do português. A partir dessa observação, surgiu o interesse em verificar se o mesmo ocorria com outros adultos surdos alfabetizados. Assim, o presente trabalho tem como ponto de partida essa pesquisa ${ }^{2}$, utilizando o mesmo tema - "violência", mas focalizando especificamente a questão da coesão textual. A coerência textual também foi analisada, porém, em virtude do espaço disponível, será apresentada em outro artigo oportunamente.

Pesquisas ${ }^{3,6-8}$ realizadas no Brasil têm apontado dificuldades na compreensão da escrita do português por parte de pessoas surdas, evidenciando nos textos produzidos uso diferenciado ou escas- 
sez de categorias gramaticais, uso restrito dos verbos e das preposições, utilizando mais as que têm sentido lexical do que função sintática. Algumas dessas características foram atribuídas a influência da Libras na construção textual e na estruturação frasal do português escrito ${ }^{3,6-8}$, parecendo indicar que a aprendizagem da modalidade escrita do português estaria sendo prejudicada pela Libras, quando a hipótese mais plausível é de que o ensino do português não estaria levando em conta a existência de uma primeira língua diferente do português $^{9,10}$.

A coesão textual faz parte do sistema de uma língua e refere-se à presença de ligação entre os elementos do texto, formando sequências com sentido por meio de mecanismos que marcam algumas relações entre enunciados ou partes deles ${ }^{11}$. Apesar de se tratar de uma relação semântica, é realizada pelo sistema léxico-gramatical. Ao estabelecer relações de sentido, a coesão relaciona-se aos recursos semânticos pelos quais uma oração se liga com a anterior. Existem duas formas de coesão textual: referencial e sequencial ${ }^{11}$.

Assim sendo, neste estudo, o objetivo é investigar a coesão textual e a interferência da LIBRAS em produções escritas por 4 adultos surdos, usuários da Língua Brasileira de Sinais, alfabetizados, integrantes de um grupo de discussão nessa língua, sobre o tema violência, coordenado por uma intérprete fluente.

\section{MÉTODOS}

Participaram deste estudo descritivo qualitativo, quatro adultos surdos sinalizadores, fluentes em LIBRAS da comunidade surda de uma cidade do interior do Estado de São Paulo e um participante ouvinte fluente em LIBRAS, que desempenhou o papel de coordenador do grupo de discussão em LIBRAS sobre violência. Esse grupo já havia participado anteriormente de estudos que envolviam discussões sobre o tema violência, portanto todos os participantes deviam apresentar conhecimento sobre este tema, pois vivenciaram aproximadamente 4 horas de discussão sobre o mesmo. Esta discussão foi direcionada por intérprete fluente em LIBRAS.

Os participantes surdos foram indicados por $\mathrm{P} 1$, P2, P3 e P4.

$P 1$ é do sexo feminino, com 21 anos de idade, e tem perda profunda bilateral. Estudou até a $6^{a}$ série do Ensino Fundamental em programa de inclusão parcial. $\mathrm{Na} 7^{\mathfrak{a}}$ série, inseriu-se em programa de inclusão total. Usa a Libras fluentemente e muito pouco a Leitura Orofacial.
P2 é do sexo masculino, com 18 anos de idade. Apresenta perda profunda e bilateral. Estudou até a $6^{a}$ serie do Ensino Fundamental em programa de inclusão parcial. $\mathrm{Na} 7^{\mathrm{a}}$ serie, inseriu-se em programa de inclusão total. Faz uso da Libras fluentemente e muito pouco da Leitura Orofacial.

P3 é do sexo masculino, com 18 anos de idade. Apresenta perda profunda e bilateral. Está na 6 ${ }^{\text {a }}$ serie do Ensino Fundamental no programa de inclusão parcial. Faz uso apenas da Libras e fluentemente.

P4 é do sexo masculino, com 21 anos de idade. Apresenta perda severa e bilateral. Está na $8^{\mathrm{a}}$ serie do Ensino Fundamental no programa de inclusão parcial. Faz uso da Libras fluentemente e da leitura orofacial.

Foram considerados como material de pesquisa os textos escritos pelos participantes sobre o tema violência.

Após a assinatura do Termo de Consentimento Livre e Esclarecido, foi realizada a coleta de dados. Para o presente estudo, os participantes se reuniram durante dois encontros, com duração de duas horas cada um, em um local conveniente, na mesma cidade, para discutir novamente sobre o tema violência. Ao final das reuniões, cada surdo participante produziu um texto escrito sobre violência, a pedido do coordenador do grupo, tomando como base todo conhecimento adquirido por eles nas discussões anteriores. $O$ foco do presente estudo está na coesão da escrita e não no conteúdo das discussões realizadas anteriormente.

Quando o texto não foi compreendido, o intérprete fez perguntas a seu autor, enquanto as pesquisadoras anotavam as explicações em um papel à parte, a fim de realizar sua correção. As correções estão marcadas em negrito. Os nomes indicados nos textos foram modificados para garantir o anonimato. O contexto abordado pelo participante é apresentado introdutoriamente, antes de seu texto. As linhas dos textos produzidos por escrito foram destacadas alfabeticamente para facilitar a análise de cada enunciado.

Estudo aprovado pelo Comitê de Ética em Pesquisa (Protocolo 421/03).

Os dados foram analisados qualitativamente, quanto ao conteúdo, tendo como critérios de análise dos textos, a coesão referencial e a coesão sequencial ${ }^{12}$.

\section{RESULTADOS}

\section{Escrita da participante 1:}

P1: Relata em seu texto uma discussão que teve com uma amiga devido aos ciúmes desta por causa do namorado. 
Texto escrito: Eu Fabiana lembra passado ano 4. Muito difícil discutir você Juliana, mas não pode discutir eu Fabiana. Chato falar Juliana coisa eu Fabiana saber. Verdade você ciúmes Juliana.

Texto corrigido: Eu, Fabiana, lembro-me do ano passado, 2004. É muito difícil discutir com você, Juliana, mas você não pode discutir comigo. É chato falar, Juliana, as coisas que eu sei. A verdade é que você tem ciúmes, Juliana.

\section{Escrita do participante 2:}

P2: Relata uma experiência desagradável vivida com um amigo, que o convidou a ir a sua casa, mas o deixou esperando por longo tempo, o que o fez ficar aborrecido.

Texto escrito: Um amigo o Carlos convidar mim de muito legal. Ele falou o Roberto vai sua casa precisar conversar só amanhã. Eu achei ficar aqui espera por o amigo demora. Eu achei mentira.

Texto corrigido: Um amigo, o Carlos, convidou-me porque é muito legal. Ele falou que o Roberto vai a sua casa porque precisam conversar sozinhos amanhã. Eu fiquei aqui esperando, porque o amigo demorou. Eu achei mentira.

\section{Escrita do participante 3:}

P3: Relata um episódio em que vai a uma loja e pergunta o preço de um aparelho, quando retorna e pergunta novamente, fica surpreso porque o preço aumentou.

Texto escrito: $O$ Marcelo foi shopping perguntar qual dinheiro game. Homem responder $\mathrm{R} \$$ 300,00 , perguntar desculpa. Depois voltar shopping, eu quero perguntar qual dinheiro Marcelo susto dinheiro por aumentar.

Texto corrigido: $O$ Marcelo foi ao shopping perguntar qual o preço do videogame. $\mathbf{O}$ homem responde: $R \$ 300,00$. Disse obrigado. Depois voltei ao shopping e perguntei qual era o preço do videogame. Marcelo levou um susto porque o preço aumentou.

\section{Escrita do participante 4:}

P4: Relata um fato que ele presenciou em São Paulo, na Praça da Sé, onde viu muitas pessoas, de diferentes idades, pedindo e roubando.

Texto escrito: É muito triste, é crianças, adolescentes, jovens e adultos, assaltando, roubando as pessoas até mesmo mata. São crianças e adultos que não tem comida e nem dinheiro por isso ele rouba para poder sobreviver ou então essas pessoas são viciadas drogas e rouba para poder fumar. Triste, oprimida, com medo, assustada. Se sente perseguida e tem sonhos horríveis. Eu achou colocava vários guardas policial ou redor da praça vigiando e cuidada das pessoas.
Texto corrigido: É muito triste ver crianças, adolescentes, jovens e adultos assaltando e roubando as pessoas, até mesmo matando. São crianças e adultos que não têm comida e nem dinheiro, por isso eles roubam para poder sobreviver ou então essas pessoas são viciadas em drogas e roubam para poder fumar. São pessoas tristes, oprimidas, com medo e assustadas. Sentem-se perseguidas e têm sonhos horríveis. Eu acho que deveriam colocar vários policiais ao redor da praça, vigiando e cuidando das pessoas

\section{DISCUSSÃO}

Nesta temática será discutida cada uma das produções separadamente e posterior fechamento das mesmas.

\section{Discussão da escrita referente ao participante 1:}

A - Eu Fabiana lembra passado ano 4.

Ocorre uso de pronome pessoal associado ao nome. Em Libras, quando se fala de si próprio, fazse seu sinal (cada participante tem um sinal). Como utiliza o próprio nome quando sinaliza, faz essa referência na escrita, evidenciando desconhecimento de que, nesta, o pronome pessoal "eu" basta como referência a si mesmo. Omite o pronome "me" e utiliza o verbo lembrar concordando em $3^{\text {a }}$ pessoa, conjugando-o de acordo com "Fabiana" e não com "eu". Há inversão de "ano passado" para "passado ano" e utilização de 4 para referir-se a 2004. A vírgula não foi utilizada. Essa frase apresenta transposição direta do uso das regras da Libras para o português escrito.

B - Muito difícil discutir você Juliana, mas não pode discutir eu Fabiana.

Observa-se ausência do verbo "ser" conjugado na $3^{\text {a }}$. pessoa (é), iniciando a frase; ausência do conectivo "com", o que parece estar subentendido pela autora do texto. Parece que ela escreve da forma como se expressa em Libras. Isso também é frequentemente observado em pessoas ouvintes que estão aprendendo a escrever e "escrevem do jeito que falam", isto é, transpõem diretamente da fala para a escrita, não tendo ainda compreendido as diferenças entre as duas modalidades da língua.

Há uso incorreto de vírgula. Ocorre supressão da forma remissiva referencial "você" (Juliana) na oração subordinada e substituição do pronome "comigo" pelo uso do pronome mais nome ("Eu Fabiana").

C - Chato falar Juliana coisa eu Fabiana saber.

Ocorre ausência do verbo "ser" conjugado na $3^{a}$. pessoa (é) no início da frase. Omissão das vírgulas entre os nomes. Omissão do artigo definido "as". Ausência da concordância nominal, utilizando 
"coisa" ao invés de coisas. Ausência do "que" para se referir às coisas sabidas. Ausência de conjugação do verbo "saber" na 1‥ pessoa (sei). A escrita parece estar contaminada pela Libras. Mas, o problema da concordância nominal também é comum entre ouvintes, tanto na fala como na escrita (ex: as coisa).

D - Verdade você ciúmes Juliana.

Há ausência do artigo definido "a", iniciando a frase, e do verbo "ser" conjugado na $3^{\text {a }}$. pessoa (é). Ausência da expressão "é que", como partícula explicativa. Ausência do verbo "ter", conjugado na 3a . pessoa, concordando com o pronome "você". Ausência da vírgula para apresentar o vocativo Juliana.

À primeira vista, esse texto parece incoerente, porém, ele apresenta uma sequência. Há encadeamento dos fatos, evidenciando coesão sequencial, apesar de destituído de elementos que deveriam estar presentes gramaticalmente. A coesão referencial existe até certo ponto, pois há remissão a fatos que ocorreram e são necessários para exposição das idéias seguintes. Porém, destituído de conectivos, o encadeamento das frases dificulta a compreensão pelo leitor. O conteúdo do texto relaciona-se ao tema proposto (violência), pois trata de uma discussão ocorrida entre ela e uma amiga.

\section{Para o participante 2, a partir de sua escrita, discutiu-se:} legal.

A - Um amigo o Carlos convidar mim de muito

Há ausência de vírgulas. A colocação do artigo definido antes do nome próprio é uma construção típica da oralidade e comum quando se faz referência a alguém próximo (a Maria, o João). No texto, não parece haver incorreção. Porém, o verbo está no infinitivo, há substituição de "me" por "mim", não aparece conectivo de justificativa (porque), há ausência do verbo "ser" conjugado na 3a . pessoa do presente do indicativo (é). A preposição "de", apesar de utilizada de forma inapropriada, parece indicar uma busca de compreensão do português.

B - Ele falou o Roberto vai sua casa precisar conversar só amanhã.

Sujeito e verbo estão corretos, mas ocorre omissão da conjunção subordinativa (que) para completar o verbo "falar". O verbo "ir" está correto, mas exige a preposição "a", que foi omitida. Há ausência do conector de justificativa (porque), incorreção da conjugação do verbo "precisar", em função de sujeito composto (ele e Roberto). O termo empregado, "só", é um advérbio de tempo, mas foi empregado em lugar de "sozinhos", que se refere ao sujeito composto funcionando como adjetivo. Parece que as regras que regem verbos transiti- vos diretos e indiretos no português não foram bem compreendidas, neste caso.

C - Eu achei ficar aqui espera por o amigo demora.

O verbo "achar" parece inadequado, considerando suas explicações sobre o texto. O verbo "ficar" está dentro do contexto, porém de modo incorreto. O verbo "esperar" parece ter sido substituído pelo substantivo (espera). O substantivo "demora" foi usado no lugar do verbo.

D - Eu achei mentira.

Esta frase expressa a conclusão a que o participante chegou em relação à situação que viveu $e$ não parece apresentar inadequação. É esta afirmação que revela o caráter de percepção da situação como uma forma de violência simbólica, evidenciando o desrespeito do amigo ao mentir para ele.

Apesar de fazer referência ao tema proposto (violência), apresenta desconhecimento de regras de pontuação, coesão sequencial ${ }^{11}$ prejudicada, mas há alguns elementos gramaticais necessários à coesão referencial ${ }^{11}$, o que indica uma tentativa de construção do português. No texto como um todo, a coesão referencial é falha.

\section{Para o participante 3:}

A - O Marcelo foi shopping perguntar qual dinheiro game.

Utiliza seu nome próprio ao invés do pronome pessoal (eu), mas faz a concordância verbal adequada ao sujeito da frase (Marcelo foi). O verbo "ir" exige preposição "a", neste caso, juntamente com o artigo "o", indicando lugar. Os elementos "perguntar qual" estão corretos, mas faz uma substituição dentro do mesmo campo semântico, "o preço" por "dinheiro". Esta substituição parece estar relacionada ao sinal (que é o mesmo para as duas palavras, e que em Libras se diferenciam em função do contexto em que é utilizado), indicando interferência da língua de sinais na escrita. Ocorre ausência do conectivo "do", que indica uma relação de matéria. A expressão "game" é utilizada comumente como sinônimo de videogame. Interessante a escrita correta de shopping e game, duas palavras inglesas.

B - Homem responder $\mathrm{R} \$ 300,00$, perguntar desculpa.

A frase inicia sem o artigo definido "o" homem, o que remeteria a alguém que trabalha na loja, embora desconhecido. Em seguida, o verbo aparece inadequadamente no infinitivo. Na parte final da frase, torna-se evidente uma confusão por parte do autor do texto, no que se refere ao próprio vocabulário da Libras, quando tentou se expressar por meio do português escrito. O participante escreveu "perguntar desculpa" e, quando questionado pelo intérprete em Libras, respondeu que quis dizer "obrigado". Em 
Libras, "perguntar", "desculpar" e "agradecer" são sinalizados de formas diferentes. Isso parece evidenciar que este participante conhece a escrita de muitas palavras em português, mas, nem sempre as aplica de acordo com o que deseja expressar.

C - Depois voltar shopping, eu quero perguntar qual dinheiro.

A sequência temporal evidencia-se pela palavra "depois", mas a conjugação verbal falha, assim como o estabelecimento da relação entre o verbo e o predicado, que, neste caso, exige uso da preposição "a" mais o artigo "o". A continuação do texto, segundo sua explicação ao intérprete, exige o conectivo "e" seguido do verbo perguntar na 1 a pessoa do pretérito (perguntei), do artigo "o" e da palavra preço, que foi novamente substituída pela palavra "dinheiro". Observa-se interferência da língua de sinais em sua escrita.

\section{D - Marcelo susto dinheiro por aumentar.}

Utiliza o nome próprio em lugar do pronome pessoal, mas desta vez omite o verbo ("levar"). Em seguida, inverte a ordem das palavras e substitui "preço" por "dinheiro". Ocorre, na frase, a omissão do conector que expressa justificativa e emprego incorreto do verbo no infinitivo.

Apesar da influência da língua de sinais, o texto apresenta pontuação e estruturas do português escrito. Há coesão sequencial ${ }^{11}$, garantindo encadeamento de ideias pela progressão por continuidade, porém, em algumas partes, é necessário perguntar o que quis dizer. Nota-se conhecimento de alguns elementos gramaticais do português e uso apropriado. O uso da expressão adverbial de tempo (depois) garante a coesão, mas os tempos verbais são impróprios para narração, pois mistura tempos verbais na mesma frase. Ele define o lugar do acontecimento dos fatos e, com isso, faz um encadeamento de idéias, garantindo certa coesão textual.

A coesão referencial ${ }^{11}$ é adequada em termos de uso de estruturas gramaticais e lexicais, embora algumas sejam utilizadas de modo incorreto, do ponto de vista da escrita formal.

Embora não esteja clara no texto a relação com o tema proposto, violência, esta aparece de forma velada como desrespeito ao consumidor, que, assustado, se pergunta "como pode o preço ter subido tão depressa?" Assim como ele, todos nós consumidores, por vezes, nos assustamos com a variação dos preços de diversos tipos de produtos.

\section{Finalmente para a produção da escrita do participante 4 , discutiu-se:}

A - É muito triste, é crianças, adolescentes, jovens e adultos, assaltando, roubando as pessoas até mesmo mata.
O texto inicia expressando o sentimento diante de um determinado contexto social. A frase apresenta duas falhas, do ponto de vista do português formal, ausência do verbo "ver" (trocado pelo verbo "ser" na 3a. pessoa do presente do indicativo - é) e a conjugação do verbo matar, que deveria estar no gerúndio. Há emprego incorreto de vírgulas.

B - São crianças e adultos que não tem comida nem dinheiro por isso ele rouba para poder sobreviver ou então essas pessoas são viciadas drogas e rouba para poder fumar.

Utiliza corretamente o verbo "ser" e a concordância verbal e nominal, mas o verbo "ter" deve receber acentuação na sua conjugação na $3^{\text {a }}$. pessoa do plural. Há ausência da vírgula antes da conjunção explicativa e emprego inadequado do pronome pessoal, que deveria estar no plural ("eles") e em concordância verbal com o verbo roubar ("roubam"). Ausência da preposição "em".

C - Triste, oprimida, com medo, assustada.

Há ausência de grupo nominal exercendo função remissiva (são pessoas), resultando em ausência de concordância nominal, isto é, as palavras deveriam estar no plural (tristes, oprimidas, assustadas).

D - Se sente perseguida e tem sonhos horríveis.

Embora alguns gramáticos não considerem mais um erro o uso da próclise neste caso, não se deve iniciar período com pronome átono: "se sente" por "sentem-se". Para concordar com a frase anterior, deveria utilizar o plural, pois se remete às pessoas.

E - Eu achou colocava vários guardas policial ou redor da praça vigiando e cuidada das pessoas.

Esta frase parece um tanto confusa. Observase conjugação inadequada do verbo "achar", que deveria estar no presente do indicativo (acho), ausência da conjunção integrante subordinativa "que" e do verbo "dever", conjugado no futuro do pretérito, seguido do verbo "colocar", no infinitivo. Há emprego desnecessário de duas palavras de significado semelhante, guardas e policial. A preposição "ou" está empregada inadequadamente, pois a frase requer a expressão "ao redor de". Uma vez que o primeiro verbo foi utilizado no gerúndio, para indicar a tarefa dos policiais ("vigiando"), o segundo verbo aditivo também deveria ser conjugado dessa forma ("cuidando").

Há elementos que estabelecem relação direta com o tema proposto, deixando claras suas ideias. Observa-se presença de coesão sequencial e referencial. $\mathrm{O}$ autor utiliza as estruturas necessárias para construção da coesão textual ${ }^{11}$, apesar de conter pequenos desvios.

Em um primeiro olhar, percebe-se a interferência da Libras nas redações destes quatro participantes surdos. Algumas construções, tais como as 
do participante 1, deixam clara a superposição das duas línguas (Libras e Português).

Observou-se que os textos, por si sós, são difíceis de serem compreendidos sem a interação direta com o participante. Essa compreensão da diferença entre a língua usual e a língua escrita é difícil para qualquer aprendiz, mas fica mais evidente quando se trata de aprender a escrever em uma segunda língua, cuja estrutura é muito mais diferente do que a existente entre a mesma língua falada e escrita.

Os resultados obtidos neste estudo estão de acordo com os apontados em outras pesquisas sobre as produções escritas de pessoas surdas ${ }^{2,3,6}$. É importante apontar a existência desses dados para os professores que estão nas salas de aula, e que trabalham com os surdos, mostrando a eles a interferência da Libras na aprendizagem do português escrito, por parte de surdos, e ressaltando que estas duas línguas apresentam estruturas diferentes, o que exige modos de conduzir o processo ensino-aprendizagem mais adequados às características dos aprendizes.

A escrita contrasta com a riqueza da prosódia da Libras. A interferência da sintaxe da Libras no português escrito deve-se à não-correspondência direta entre as duas línguas, às diferentes estruturas lexicais e às limitações da escrita em relação ao diálogo face a face.

O português é aprendido pelo surdo como uma segunda língua, com todas as dificuldades inerentes a esse processo. Um estudo sobre a psicogênese da língua escrita evidenciou que essa dificuldade está presente na alfabetização de qualquer criança comum, que vai aprender a escrever a mesma língua que fala e à qual está exposta em sua comunidade linguística desde bebês. $O$ que se está observando no grupo de surdos estudado aqui, e em outros estudos, não é diferente do que essas pesquisadoras observaram em seus estudos sobre a aquisição da língua escrita. No entanto, anterior à dificuldade escolar relativa à escrita, existe a dificuldade de aquisição de uma primeira língua por parte desses surdos.

A língua escrita tem suas próprias regras e recursos de linguagem, que se diferenciam das regras da Libras, e isso deve ficar claro para o professor, que precisa conhecer a construção linguística dessas duas línguas tão diferentes.

Nesse sentido, observa-se que, para os participantes 1, 2 e 3, há muito que se construir em termos de português escrito, tomando como base que o sentido do que escrevem nem sempre está no texto, mas se constrói a partir dele no curso de uma interação humana e dialógica de qualidade. É como se a representação semântica das palavras colocadas no texto fosse suficiente para que as frases escritas fossem compreendidas. Suas produções estão mais vinculadas ao contexto do que às estruturas das regras gramaticais do português.

A análise dos quatro textos produzidos pelos participantes evidencia a presença de coesão textual, sequencial e referencial ${ }^{11}$, apesar de prejudicada em muitos momentos, pela ausência de conectivos, equívocos na conjugação verbal e ausência de domínio das regras gramaticais da Língua Portuguesa. $O$ texto mais comprometido em termos de coesão foi o do participante 2 , enquanto que o menos comprometido foi o do participante 4 .

Os participantes são como aprendizes de uma segunda língua, que é o português escrito, e tornase premente ficarem claras para eles as diferenças entre as línguas. As ocorrências encontradas nas análises da escrita, ao invés de serem um empecilho, devem servir de referência pedagógica para o trabalho com a segunda língua do surdo. O ideal seria que professores e surdos fizessem uso da Libras e que esta se constituísse como elemento central do desenvolvimento intelectual e linguístico dessas pessoas.

\section{CONCLUSÃO}

A competência na escrita dos participantes melhorou conforme aumentou o nível de escolaridade e sua exposição a Libras com interlocutores de qualidade, o que se evidenciou principalmente no participante 4 .

Todos os textos analisados apresentaram coesão textual, sequencial e referencial, apesar de comprometida pela falta de domínio da Língua Portuguesa e pela contaminação de elementos da Libras. Além disso, foi possível observar que, quanto melhor a coesão textual, menor a necessidade de explicações adicionais para que o leitor compreenda a mensagem, e vice-versa.

\section{AGRADECIMENTOS}

Agradecemos à Fapesp e às Profas. Ilmara Fátima de Moraes, Roselene dos Anjos, e Patrícia Moreira Duarte pelas contribuições. 


\section{ABSTRACT}

Purpose: to investigate text cohesion in written productions of four deaf male adults using Brazilian Sign Language (Libras) and write in Portuguese. Participants integrate a discussion group on violence using that language coordinated by a fluent interpreter. The study also verifies possible interference of Libras on writing in Portuguese. Methods: after a few sessions, a discussing the theme violence, each deaf participant wrote a text on a violence situation. These texts were analyzed qualitatively as for their cohesion. Results: the study pointed out the existence of sequential and referential text cohesion in all the analyzed texts, although compromised. There was interference of Libras in their writing. The produced texts related in some way to symbolic violence. The texts per se were difficult to understand without direct interaction with the participant. Despite difficulties in comprehension of writing language whose structure is very different from the sign language, it became clear that these deaf persons could construct texts with sense and cohesion. Conclusion: the texts produced by the studied deafs have cohesion, although the interference of Libras was harmful in some cases as for the reader's comprehension. As text cohesion diminishes, there is more need for explanations by the author about the meaning of the said text.

KEYWORDS: Deafness; Language; Writing; Education

\section{REFERÊNCIAS}

1. Marin CR, Góes MCR. A experiência de pessoas surdas em esferas de atividade do cotidiano. Cad CEDES. 2006; 26(69):231-49.

2. Almeida EOC. Leitura e surdez. Um estudo com adultos não oralizados. Rio de Janeiro: Revinter; 2000.

3. Silva MPM. A construção de sentidos na escrita do aluno surdo. São Paulo: Plexus; 2001.

4. Angelides $P$, Aravi C. A comparative perspective on the experiences of deaf and hard of hearing individuals as students at mainstream and special schools. Am Ann Deaf. 2006-2007; 151(5):476-87. 5. Guarinello AC, Gregolin RM. As produções escritas de sujeitos surdos. Rev Letras. 2005; 65:135-51.

6. Guarinello AC, Massi G, Berberian AP. Surdez e linguagem escrita: um estudo de caso. Rev Bras Educ Espec. 2007 maio-ago; 13(2):205-18.
7. Monreal ST, Hernández RS. Reading levels of Spanish deaf students. Am Ann Deaf. 2005; 150(4):379-87.

8. Berberian AP, Bortolozzi KB, Guarinello AC. Recurso terapêutico fonoaudiológico voltado à linguagem escrita do surdo: o software "Surdo aprendendo em silêncio". Dist Comun. 2006; 18(2):189-99.

9. Antia SD, Reed S, Kreimeyer KH. Written language of deaf and hard-of-hearing students in public schools. J Deaf Stud Deaf Educ. 2005; 10(3):244-55.

10. Guarinello AC, Berberian AP, Santana APO, Bortolozzi KB, Schemberg S, Figueiredo LC. Surdez e letramento: pesquisa com surdos universitários de Curitiba e Florianópolis. Rev Bras Educ Espec. 2009 jan-abr; 15(1):99-120.

11. Koch IGV. A coesão textual. 18. ed. São Paulo: Contexto; 2003.

RECEBIDO EM: 25/01/2009

ACEITO EM: 08/09/2009

Endereço para correspondência:

Elizabeth Oliveira Crepaldi de Almeida

Rodovia Geraldo Scavone, 1000 - Lote 68

Jacareí - SP

CEP: $12300-000$

E-mail: nelson_almeida@uol.com.br 